\title{
ADH activity and ethanol tolerance in third chromosome substitution lines in Drosophila melanogaster
}

\author{
Hervé Merçot and \\ Liliane Massaad
}

\author{
Laboratoire de Génétique des Populations Universités \\ Paris VI \& VII, Tour 42-4, 2 place Jussieu, 75251 \\ Paris Cedex 05, France.
}

\begin{abstract}
In vitro ADH activity and ethanol tolerance were studied in males of a series of third chromosome substitution lines in Drosophila melanogaster. The lines were divided into those with a random third chromosome from a vineyard population (VO lines) and those with a selected third chromosome from males obtained after an egg-to-adult ethanol survival test on the F4 of the previous population (VE lines). Both ADH activity and ethanol tolerance varied significantly among the lines, but the characters showed no significant correlation. Ethanol tolerance (at the higher ethanol concentrations) was higher in the selected lines (VE lines) but ADH activity was not. In our lines, the in vitro ADH activity variability, linked to the regulatory genes (located on the third chromosome) and unrelated to the polymorphism of the $A d h$ locus (located on the second chromosome), is not involved in the ethanol tolerance variability. The data suggest that in this population ethanol tolerance was acquired in nature, at least partially, by means other than increasing $\mathrm{ADH}$ activity.
\end{abstract}

\section{INTRODUCTION}

Drosophila melanogaster is remarkable for its capacity to tolerate and exploit the presence of alcohols in its habitat (Monclus and Prevosti, 1978-79; David and Van Herrewege, 1983). In this adaptation the enzyme alcohol dehydrogenase (ADH EC 1.1.1.1) plays a key role. Indeed $\mathrm{ADH}$ ensures both metabolic use and detoxification of ethanol (Van Herrewege and David, 1980). The presence of an active $\mathrm{ADH}$ is necessary to the survival of the flies in ethanol supplemented media (David et al., 1976; Middleton and Kacser, 1983; Fretth et al., 1986).

There are two sources of variation for the in vitro ADH activity level:

-Firstly, the polymorphism of the $A d h$ structural gene, with different allozyme activities (Chambers et al., 1984). All natural populations contain two widespread alleles, $A d h^{S}$ and $A d h^{F}$ (Oakeshott et al., 1982; David et al., 1986). Generally flies from homozygous $A d h^{F F}$ strains possess greater in vitro ADH activity than those from homozygous $A d h^{S S}$ strains. This difference is due for the most part to the higher number of ADH molecules associated with the $A d h^{F-}$ genotype (Lewis and Gibson, 1978; McDonald et al., 1980), but also to the greater activity of the catalytic-centre of the ADH-F allozyme (Winberg et al., 1985).
- Secondly, the existence of polymorphic regulatory genes (Ayala and McDonald, 1980). The role of these regulatory (or modifier) genes is to act on the amount of synthesized enzyme (Maroni et al., 1982), or even on the enzyme stability (King and McDonald, 1987). It has been shown that these modifiers of ADH activity are located on the $\mathrm{X}$, second and third chromosomes (Pipkin and Hewitt, 1972; Ward, 1975; Barnes and Birley, 1978; McDonald and Ayala, 1978; Maroni et al., 1982).

Extensive experiments have been carried out in order to emphasize the selective significance of the alcohol dehydrogenase polymorphism on the ethanol tolerance (see Van Delden, 1982, for review, and Oakeshott et al., 1984, for controversy). However, few experiments have been made on the relationship between the ethanol tolerance and the ADH activity variability which is unrelated to the structural locus. The first result concerned an experiment by David and Bocquet (1977), in which they were able to increase the median lethal dose $\left(L D_{50}\right)$ of ethanol by more than 100 per cent in their selected strain. No evidence was found of the existence of structural differences in ADH between selected and control strains. The selected strain, however, had higher ADH activity (McDonald et al., 1977). Other authors have described a positive relationship between ethanol tolerance and $\mathrm{ADH}$ activity in strains homozygous for the same allele 
of Adh. Thompson and Kaiser (1977) found a positive correlation between egg-to-adult survival and ADH activity when two $A d h^{\text {SS }}$ strains, differing in activity, were tested on ethanol-supplemented food. Nevertheless this result is not unambiguous, because the potato-flake dextrose medium used seems to be, itself, a nutritive selective agent. Kamping and Van Delden (1978) studied seven $A d h^{F F}$ homozygous lines and one Adh-null line. Although the positive correlation observed between $\mathrm{ADH}$ activity and $\mathrm{LD}_{50}$ of ethanol included the Adh-null strain, the correlation remained significantly positive considering only the seven $A d h^{F F}$ strains. Nevertheless one must point out that this result was due only to one strain which showed an atypically low activity. Furthermore, none of these experiments had used the chromosome substitution lines which are the most appropriate for the study of variations of enzyme activity linked to modifier genes in $D$. melanogaster (Laurie-Ahlberg et al., 1980; 1982). Therefore we investigated the existence of a relationship between the $\mathrm{ADH}$ activity variation due to regulatory genes and the ethanol tolerance in chromosome substitution lines.

The present study concerns only the effects of the third chromosome. Since the Adh locus is located on the second chromosome $(2-50 \cdot 1)$, the choice of the third chromosome avoids:

-the variability linked to the different alleles of Adh,

- the possibility of linkage disequilibrium between the Adh locus and modifier genes of $\mathrm{ADH}$ activity, -the difficulty of distinguishing between cis- and trans-acting factors. Here, only trans-acting factors need to be invoked to explain the observed differences.

\section{MATERIALS AND METHODS}

\section{(i) Strains}

(a) Balancer stock: the substitution of third chromosomes onto an isogenic background was carried out using a balancer stock, 39A1. The procedure for the constitution of the 39A1 stock is given in fig. 1, the male used originated from the SA-FIV population (Merçot, 1985). Chromosome II of 39A1 (marked II in fig. 1) carries the $A d h^{\mathrm{s}}$ and purple alleles. Therefore $39 \mathrm{~A} 1$ is symbolised by: $\mathrm{X}^{\mathrm{i}} / \mathrm{X}^{\mathrm{i}} ; \mathrm{pr} / \mathrm{pr} ; \mathrm{Ser} / \mathrm{Sb}$ in fig. 2.

(b) third chromosome lines: the procedure for substitution of third chromosomes into an isogenic background is shown in fig. 2. Nevertheless, the substitution lines are different also for the $\mathrm{Y}$ chromosome (from the FO males) and the origin of the little fourth chromosome is uncontrolled. But the size of the $\mathrm{Y}$ chromosome is insignificant and the fourth is 23 times smaller than the third chromosome. Consequently their possible effect was ignored.

(c) origin of third chromosomes: two sets of third chromosome lines were constituted: (1) the VO lines derived from wild males trapped in Venteuil (Marne, France) in October 1984, (2) the $\mathrm{VE}$ lines derived from males obtained from an egg-to-adult survival experiment on 18 per cent of

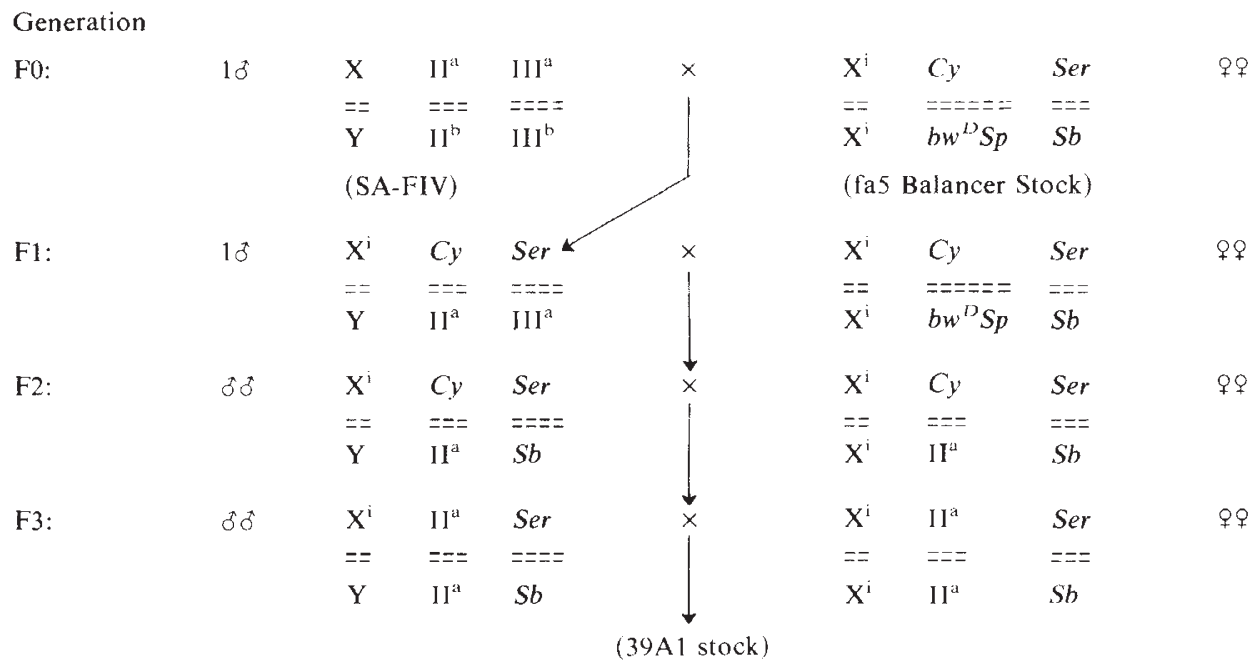

Figure 1 Mating scheme used to obtain the 39A1 balancer stock. 


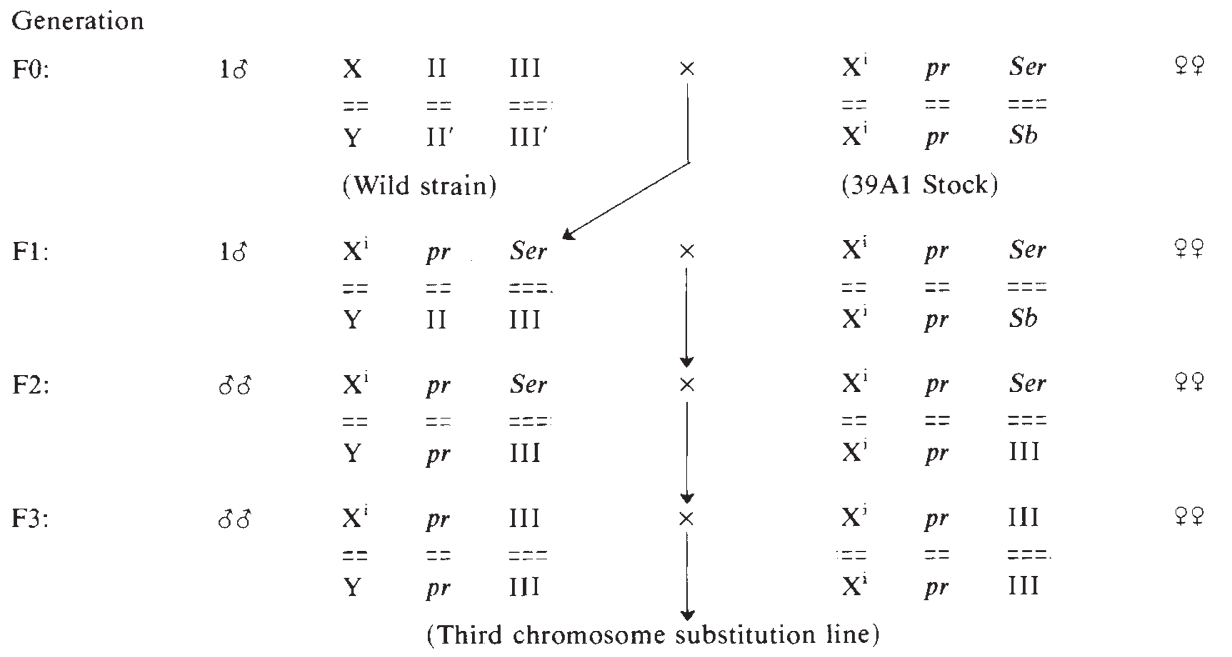

Figure 2 Mating scheme used to obtain strain homozygous for a third chromosome in the isogenic 39A1 background. In F2, for the second chromosome, a fly with the $p r / / p r$ genotype is distinguished from a fly with the II//pr because the former has the pr phenotype whilst the latter has a wild phenotype for eye-color.

ethanol (David et al., 1986); this experiment was carried out, on one single generation, with the F4 of the Venteuil population and caused 74 per cent of mortality.

\section{(ii) $A D H$ activity}

(a) Assays: the assay procedure for in vitro ADH activity is described by Merçot and Higuet (1987).

(b) rearing conditions and sampling: for each isogenic line 600 eggs were placed in two bottles (300 eggs per bottle) of cornmeal axenic medium with killed yeast (David, 1962). The off-spring were reared at $25^{\circ} \mathrm{C}$, collected within $18 \mathrm{~h}$ of emergence. Adult males were aged in three groups of 15 individuals for seven, eight and nine days on axenic medium. Live flies were then weighed and their ADH activity measured, twice, on the same day. Thus there were six samples of 15 pooled males (from two bottles and with three different ages) assayed for each line. Thirteen VO lines and 13 VE lines were analysed during March and April 1986. In order to estimate the repeatability of line differences, seven VO lines and seven VE lines were resampled in March 1987.

(c) Statistical analysis: the analysis of the $\mathrm{ADH}$ activity variations was carried out with an ANOVA with respect to three hierarchical factors, origin of the third chromosomes $(\mathrm{O})$, chromosome lines (L), bottles (B) and one cross-factor, the age of males (A).

\section{(iii) Ethanol tolerance}

(a) Experimental procedures: Experiments were carried out at $25^{\circ} \mathrm{C}$ on seven VO lines and seven VE lines during June and July 1986. Ethanol tolerance was measured according to the method of David et al. (1974). Larvae were grown at low larval density on the axenic killed yeast medium. After emergence, adult males were separated from females, and groups of 20 were kept on nutrient medium for seven days. Each group of males was then transferred into an air-tight plastic vial containing $2 \mathrm{ml}$ of a 3 per cent sucrose solution supplemented with the suitable concentration of ethanol and absorbed by a cellulose paper. For each test, five concentrations of ethanol $(5,7,9,11$ and 13 per cent) were used, with five replicates per concentration. Dead flies were counted daily for three consecutive days.

(b) Statistical analysis: For each concentration and for each day scored, we carried out the following analysis:

-comparison of the percentage of mortality between the 14 lines by the Kruskal-Wallis test, - comparison of the mean percentage of mortality between the VO lines and the VE lines by the Mann and Whitney test, - computation of the correlation coefficient, by the Spearman rank test, between the percentage of ethanol mortality of lines and both their ADH activity and their body weight. 


\section{RESULTS}

\section{(i) $A D H$ activity}

Table 1 gives the mean values, over the three days, of fresh weight, ADH activity per fly and ADH activity per $\mathrm{mg}$ of fresh weight for the 26 lines

Table 1 Means of fresh weight ( $w)$, ADH activity by fly $(\boldsymbol{A} / \mathbf{f})$ and ADH activity by $\mathrm{mg}$ of fresh weight. $(A / \mathrm{mig})$ measured in males from the VO lines and VE lines. Roman type: results from 1986; italics: results from 1987

\begin{tabular}{|c|c|c|c|c|c|c|}
\hline Lines & $w^{*}$ & $\mathrm{SE}(w)$ & $A \dagger / \mathrm{f}$ & $\mathrm{SE}(\boldsymbol{A} / \mathrm{f})$ & $A / \mathrm{mg}$ & $\operatorname{SE}(A / m g)$ \\
\hline \multirow[t]{2}{*}{ VO3A } & $0 \cdot 803$ & $0 \cdot 006$ & $2 \cdot 609$ & 0.012 & $3 \cdot 254$ & 0.021 \\
\hline & 0.850 & 0.005 & $2 \cdot 641$ & 0.012 & $3 \cdot 111$ & 0.016 \\
\hline VOIID & 0.802 & 0.003 & 2.990 & 0.014 & $3 \cdot 734$ & $0 \cdot 025$ \\
\hline VO13B & $0 \cdot 714$ & 0.003 & $2 \cdot 634$ & 0.011 & $3 \cdot 687$ & 0.015 \\
\hline \multirow[t]{2}{*}{$\mathrm{VO} 24 \mathrm{C}$} & 0.803 & $0 \cdot 004$ & $3 \cdot 275$ & 0.008 & $4 \cdot 081$ & $0 \cdot 013$ \\
\hline & $0 \cdot 866$ & $0 \cdot 004$ & $3 \cdot 310$ & 0.017 & $3 \cdot 820$ & 0.018 \\
\hline \multirow[t]{2}{*}{ VO30B } & 0.787 & $0 \cdot 002$ & $3 \cdot 018$ & $0 \cdot 014$ & $3 \cdot 835$ & 0.019 \\
\hline & 0.778 & 0.002 & $3 \cdot 195$ & 0.010 & $4 \cdot 107$ & 0.013 \\
\hline \multirow[t]{2}{*}{ VO36A } & $0 \cdot 894$ & 0.005 & 3.068 & 0.014 & $3 \cdot 436$ & 0.021 \\
\hline & 0.895 & 0.006 & $3 \cdot 195$ & 0.013 & $3 \cdot 575$ & $0 \cdot 018$ \\
\hline VO4lD & 0.770 & 0.002 & $2 \cdot 899$ & $0 \cdot 020$ & $3 \cdot 767$ & 0.026 \\
\hline VO43B & $0 \cdot 769$ & $0 \cdot 007$ & $2 \cdot 795$ & 0.017 & $3 \cdot 638$ & 0.023 \\
\hline \multirow[t]{2}{*}{$\mathrm{VO} 47 \mathrm{~B}$} & $0 \cdot 850$ & $0 \cdot 005$ & $2 \cdot 007$ & 0.017 & $2 \cdot 359$ & 0.017 \\
\hline & 0.887 & 0.003 & $2 \cdot 010$ & 0.009 & $2 \cdot 266$ & 0.009 \\
\hline VO54A & 0.747 & 0.008 & $3 \cdot(084$ & 0.012 & $4 \cdot 144$ & $0 \cdot 026$ \\
\hline \multirow[t]{2}{*}{ VO63B } & 0.883 & $0 \cdot 004$ & 3.457 & 0.013 & 3.917 & 0.016 \\
\hline & 0.886 & 0.004 & $3 \cdot 396$ & 0.019 & $3 \cdot 832$ & 0.020 \\
\hline VO64B & 0.795 & 0.005 & $3 \cdot 743$ & 0.018 & $4 \cdot 716$ & $0 \cdot 028$ \\
\hline \multirow[t]{2}{*}{ VO77A } & 0.797 & $0 \cdot 003$ & $3 \cdot 137$ & $0 \cdot 008$ & 3.936 & $0 \cdot 010$ \\
\hline & $0 \cdot 807$ & 0.002 & $2 \cdot 885$ & $0 \cdot 016$ & $3 \cdot 575$ & $0 \cdot 021$ \\
\hline $\mathrm{VO}_{\text {mean }}$ & $0 \cdot 801$ & $0 \cdot 004$ & $2 \cdot 978$ & $0 \cdot 033$ & $3 \cdot 731$ & 0.042 \\
\hline$V O_{\text {mean }}$ & 0.859 & 0.006 & $2 \cdot 947$ & 0.070 & $3 \cdot 469$ & 0.088 \\
\hline VE3D & 0.918 & 0.004 & $2 \cdot 723$ & $0 \cdot 0$ & 2.971 & 0.019 \\
\hline \multirow{2}{*}{ VEI 4 C } & 0.794 & 0.003 & $2 \cdot 199$ & 0.015 & $2 \cdot 770$ & $0 \cdot 016$ \\
\hline & 0.781 & 0.006 & $2 \cdot 180$ & 0.009 & $2 \cdot 796$ & 0.015 \\
\hline \multirow[t]{2}{*}{ VE35B } & 0.749 & 0.002 & $2 \cdot 432$ & 0.008 & $3 \cdot 246$ & 0.011 \\
\hline & 0.751 & 0.004 & $2 \cdot 396$ & 0.012 & $3 \cdot 208$ & 0.011 \\
\hline VE37F & 0.912 & $0 \cdot 005$ & $2 \cdot 999$ & 0.009 & $3 \cdot 291$ & 0.012 \\
\hline VE39F & 0.925 & 0.008 & $2 \cdot 481$ & 0.011 & 2.693 & 0.022 \\
\hline VE41F & 0.914 & $0 \cdot 002$ & $2 \cdot 700$ & 0.015 & 2.954 & 0.015 \\
\hline \multirow[t]{2}{*}{ VE42A } & 0.734 & 0.007 & $2 \cdot 910$ & $0 \cdot 015$ & 3.974 & 0.025 \\
\hline & 0.744 & 0.003 & $2 \cdot 813$ & 0.014 & $3 \cdot 784$ & 0.019 \\
\hline \multirow[t]{2}{*}{ VE46A } & $0 \cdot 806$ & 0.002 & $3 \cdot 070$ & 0.010 & $3 \cdot 810$ & 0.014 \\
\hline & 0.731 & 0.004 & 2.999 & 0.011 & $4 \cdot 110$ & 0.021 \\
\hline VE46B & 0.819 & $0 \cdot 003$ & $2 \cdot 971$ & 0.009 & $3 \cdot 629$ & $0 \cdot 014$ \\
\hline VE47A & 0.780 & 0.009 & 2.925 & 0.019 & 3.771 & 0.039 \\
\hline \multirow[t]{2}{*}{ VE51C } & 0.768 & 0.004 & $2 \cdot 949$ & 0.013 & $3 \cdot 845$ & 0.022 \\
\hline & 0.786 & 0.003 & $3 \cdot 059$ & $0 \cdot 017$ & $3 \cdot 897$ & 0.025 \\
\hline \multirow[t]{2}{*}{ VE5IE } & 0.783 & $0 \cdot 005$ & $2 \cdot 828$ & 0.013 & 3.617 & 0.024 \\
\hline & 0.797 & 0.001 & 2.923 & 0.019 & $.3 \cdot 671$ & 0.025 \\
\hline \multirow{2}{*}{ VE58B } & 0.829 & 0.003 & $3 \cdot 214$ & 0.018 & $3 \cdot 876$ & 0.021 \\
\hline & 0.838 & 0.005 & $3 \cdot 002$ & 0.019 & $3 \cdot 591$ & 0.029 \\
\hline$V E_{\text {mean }}$ & 0.825 & 0.005 & $2 \cdot 800$ & 0.022 & $3 \cdot 419$ & 0.035 \\
\hline$V E_{\text {mean }}$ & 0.775 & 0.005 & $2 \cdot 768$ & 0.045 & $3 \cdot 580$ & 0.059 \\
\hline
\end{tabular}

* in $\mathrm{mg}$.

$\dagger \mathrm{ADH}$ activity is expressed as $\Delta \mathrm{DO} \times 10^{3} / \mathrm{min}$.

$\mathrm{SE}(\mathrm{)}=$ Standard Error . analysed in 1986 and for the 14 lines retested in 1987.

It is usual to standardize the raw enzyme activity (units per fly) by dividing by the live weight per fly. We have tested the validity of this practice. For each line (i.e., for the environmental relationship between ADH activity per fly and weight of the six samples) the linear regression is not significant. Over the lines (i.e., for the genetic relationship between ADH activity per fly and weight of lines) the linear regression is also non-significant (1986: $r=-0.028,24 \mathrm{df}$, ns; 1987: $r=0.155,12 \mathrm{df}$, ns). These findings corroborate the results obtained by Birley and Marson (1981) and by Maroni et al. (1982) from their chromosome substitution lines. We have therefore used the ADH activity per fly to characterize the level of $\mathrm{ADH}$ activity for each line in the rest of this work.

Table 2 gives the results of the analysis of variance of the ADH activity per fly (data from 1986). The origin of lines (VO lines vs VE lines) has no influence, while a highly significant line effect is obvious. A significant effect of the third chromosome on the level of ADH activity per fly is observed in our sample of substitution lines. The age of males (seven, eight or nine days) has an influence on ADH activity. The activity of sevenday-old males $(A / f=2.845)$ is lower than the activity of eight- and nine-day-old males (2.919 and 2.903 , respectively). Though Dunn et al. (1969), Hewitt et al. (1974) and Ward (1975) have shown that ADH activity remains relatively constant in adults aged between 4 and 12 days, our results confirms that the in vitro $\mathrm{ADH}$ activity shows an increase with time during this period (Kerver and Van Delden, 1985). The bottle effect and the age $\times$ bottle interaction are also significant. They display an environmental effect linked to

Table 2 Analysis of variance of ADH activity per fly

\begin{tabular}{lrlll}
\hline Source & df & $\begin{array}{l}\text { Mean } \\
\text { square }\end{array}$ & $F$ & $P$ \\
\hline $\begin{array}{l}\text { Origin } \\
\quad \text { VO vs. VE) }\end{array}$ & 1 & 2.475 & $F_{24}^{1}=1.563$ & ns \\
Line (L) & 24 & 1.584 & $F_{26}^{24}=22.005$ & $* * *$ \\
Bottle (B) & 26 & 0.072 & $F_{156}^{16}=8.170$ & $* * *$ \\
Age (A) & 2 & 0.160 & $F_{52}^{2}=3.308$ & $*$ \\
O $\times$ A & 2 & 0.034 & $F_{48}^{2}=0.872$ & $n s$ \\
L $\times A$ & 48 & 0.039 & $F_{52}^{48}=0.808$ & ns \\
B $\times$ A & 52 & 0.048 & $F_{156}^{52}=5.481$ & $* * *$ \\
Error & 156 & 0.009 & & \\
\hline
\end{tabular}

* $P<0.05$. *** $P<0.001$.

ns $=$ non-significant $(P>0 \cdot 05)$. 
bottle culture and extract preparation. Nevertheless this environmental effect has not prevented the detection of an obvious genetic effect linked to the third chromosome. This evidence is strengthened by the high repeatability of the results in the 14 lines sampled about one year apart (table 1). This repeatability of the line differences in the ADH activity per fly is demonstrated by the highly significant value of the correlation coefficient $(r=$ $0.956 ; P<0.001 ; 12 \mathrm{df}$ ) (fig. 3). The same outcome is obvious for the body weight line differences $(r=0.822 ; P<0.001 ; 12 \mathrm{df})$.

\section{(ii) Ethanol mortality}

It is important to first point out that not all lines were tested for their tolerance to ethanol. In fact, the fecundity, fertility and/or viability of some lines were so low that the test of ethanol tolerance, which required a minimum number of flies, was impossible. Nevertheless the 14 lines tested (seven VO lines and seven VE lines; table 3 ) reflect satisfactorily the range of the ADH activity values of all 26 lines (table 1); and the mean ADH activity of the seven VO lines tested $(A / \mathrm{f}=2.939)$ and this of the seven $\mathrm{VE}$ lines tested $(A / \mathrm{f}=2 \cdot 800)$ are very similar to these of the early $13 \mathrm{VO}$ and $13 \mathrm{VE}$ lines (table 1).

Table 3 gives the percentage of male mortality in the 14 lines after one, two and three days of exposure to the five ethanol concentrations used (i.e., 15 observations). Each line was tested using

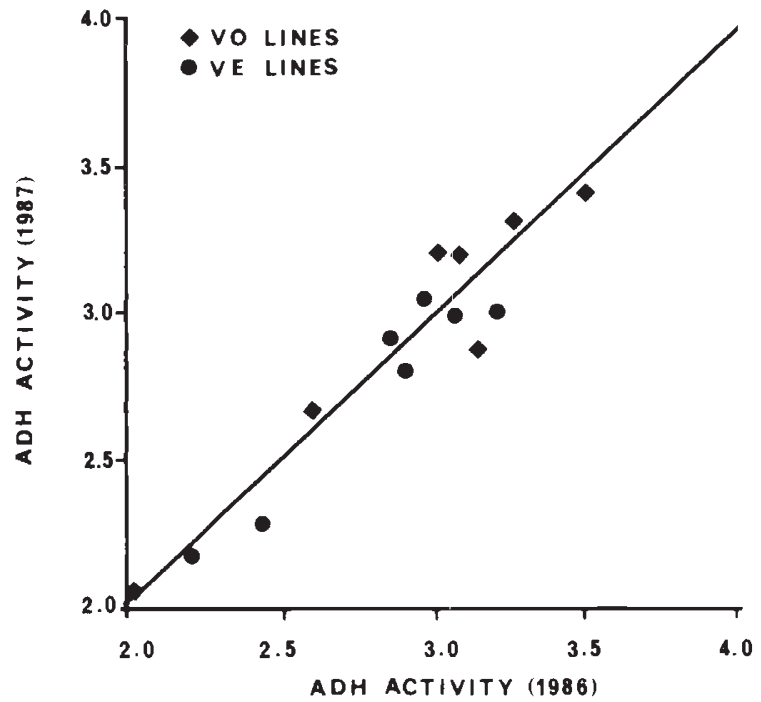

Figure 3 Repeatability of the ADH activity measurements: correlation between the measurements assayed in 1986 and 1987

three vials containing the sucrose solution without ethanol, to show an absence of mortality in control conditions.

The difference of death rate between the 14 lines was tested for each of 15 mortality observations. Table 4 gives the results of the KruskalWallis test carried out for this purpose. Except for the least severe condition (one day of exposure to a concentration of five per cent ethanol) and the

Table 3 Percentages of male mortality in the VO and Ve lines after 24 hours (D1), 48 hours (D2) and 72 hours (D3) of exposure to the different ethanol concentrations (Conc.)

\begin{tabular}{|c|c|c|c|c|c|c|c|c|c|c|c|c|c|c|c|}
\hline \multirow{2}{*}{$\begin{array}{l}\text { Conc. } \\
\text { Lines }\end{array}$} & \multicolumn{3}{|l|}{$5 \%$} & \multicolumn{3}{|l|}{$7 \%$} & \multicolumn{3}{|l|}{$9 \%$} & \multicolumn{3}{|c|}{$11 \%$} & \multicolumn{3}{|c|}{$13 \%$} \\
\hline & D1 & D2 & D3 & D1 & D2 & D3 & D1 & D2 & D3 & D1 & D2 & D3 & D1 & D2 & D3 \\
\hline $\mathrm{VO} 24 \mathrm{C}$ & 3 & 7 & 11 & 11 & 21 & 30 & 10 & 23 & 65 & 62 & 95 & 100 & 66 & 98 & 100 \\
\hline VO30B & 3 & 3 & 3 & 2 & 2 & 2 & 2 & 23 & 45 & 28 & 81 & 89 & 69 & 90 & 91 \\
\hline VO36A & 2 & 4 & 6 & 0 & 4 & 8 & 6 & 42 & 71 & 9 & 74 & 99 & 22 & 89 & 98 \\
\hline VO77A & 5 & 10 & 15 & 20 & 23 & 35 & 32. & 48 & 84 & 51 & 79 & 98 & 57 & 88 & 99 \\
\hline $\mathrm{VO}_{\text {mean }}$ & 4 & 9 & 13 & 13 & 25 & 38 & 15 & 42 & 67 & 37 & 87 & 98 & 55 & 94 & 98 \\
\hline VE14C & 10 & 20 & 42 & 11 & 36 & 73 & 18 & 46 & 63 & 34 & 65 & 93 & 27 & 77 & 99 \\
\hline VE35B & 0 & 4 & 6 & 0 & 12 & 28 & 8 & 55 & 78 & 15 & 78 & 95 & 44 & 95 & 97 \\
\hline $\mathrm{VE} 42 \mathrm{~A}$ & 0 & 1 & 1 & 4 & 16 & 41 & 6 & 42 & 88 & 21 & 64 & 88 & 75 & 87 & 100 \\
\hline $\mathrm{VE}_{\text {mean }}$ & 4 & 8 & 14 & 12 & 23 & 42 & 18 & 52 & 72 & 34 & 69 & 90 & 45 & 86 & 99 \\
\hline
\end{tabular}


Table 4 Comparison of the percentages of male mortality between the lines after each day of exposure to each ethanol concentration (Conc.): Values of $H$ from the KruskalWallis test $(13 \mathrm{df})$

\begin{tabular}{rlll}
\hline \multicolumn{4}{c}{ Days of exposure } \\
\cline { 2 - 4 } Conc. & D1 & D2 & D3 \\
\hline $5 \%$ & $19 \cdot 331$ & $27 \cdot 631^{*}$ & $35 \cdot 707^{* * *}$ \\
$7 \%$ & $30 \cdot 970^{* *}$ & $37 \cdot 222^{* * *}$ & $45 \cdot 487^{* * *}$ \\
$9 \%$ & $31 \cdot 793^{* * *}$ & $37 \cdot 806^{* * *}$ & $41 \cdot 344^{* * *}$ \\
$11 \%$ & $38 \cdot 158^{* * *}$ & $37 \cdot 218^{* * *}$ & $27 \cdot 714^{* *}$ \\
$13 \%$ & $26 \cdot 727^{*}$ & $25 \cdot 079^{*}$ & $4 \cdot 283$ \\
\hline
\end{tabular}

$$
\text { * } P<0 \cdot 05
$$

$* * P<0.01$.

$* * * P<0 \cdot 001$

Table 5 Comparison of mean percentages of male mortality between VO lines and VE lines after each day of exposure to each ethanol concentration (Conc.): Standardized values of $U$ from the Mann-Whitney test

\begin{tabular}{rlll}
\hline \multicolumn{3}{l}{ Day of exposure } \\
\cline { 2 - 4 } Conc. & D1 & D2 & D3 \\
\hline $5 \%$ & 0.546 & 0.229 & 0.135 \\
$7 \%$ & 0.534 & 0.070 & 0.781 \\
$9 \%$ & 0.699 & 1.386 & 1.239 \\
$11 \%$ & 0.511 & $2.807^{* *}$ & $2.473^{*}$ \\
$13 \%$ & 0.987 & $2.954^{* * *}$ & 0.560 \\
\hline
\end{tabular}

\footnotetext{
${ }^{*} \mathrm{P}<0.05$.

$* * \mathrm{P}<0 \cdot 01$

$* * * \mathrm{P}<0.001$
}

most severe (three days of exposure to a concentration of 13 per cent), there were always significant differences in the death rate between the 14 lines.

The comparison of the mean percentages of ethanol mortality between the VO and VE lines (table 5) shows a significantly lower mortality of the VE lines after two and three days of exposure to an ethanol concentration of 11 per cent and after two days of exposure to an ethanol concentration of 13 per cent (i.e., to the higher concentrations of ethanol). As the third chromosomes of the VE lines were from males of which the pre-imaginal development was accomplished on a larval medium with 18 per cent of ethanol (which caused a mortality of 74 per cent), these differences may display a selective effect in favour of third chromosomes which allowed a higher ethanol tolerance both in pre-imaginal and adult stages.

\section{(iii) Relationship between $A D H$ activity and ethanol mortality}

The preceding results showed both an ADH activity and ethanol tolerance variability linked to the third chromosome. The final aim of this work was to find out whether there was any correlation between these two variables. Thus we tested, with the Spearman rank test, the correlation between the ADH activity of the 14 lines and their ethanol male mortality in each of the 15 observations. Table 6 gives the value of the 15 correlation coefficients. No significant value was obtained in any case. We did not find any conclusive relationship between in vitro $\mathrm{ADH}$ activity and ethanol tolerance of males from our third chromosome substitution lines.

Table 6 Relationship between the percentage of male mortality and the ADH activity of lines: values of the Spearman's rank correlation coefficients $(\mathrm{df}=14)$, all were not significant $(P>0 \cdot 05)$

\begin{tabular}{rrrr}
\multicolumn{5}{c}{ Day of exposure } \\
\cline { 2 - 4 } Conc. & \multicolumn{1}{l}{ D1 } & D2 & D3 \\
\hline $5 \%$ & -0.051 & -0.085 & -0.071 \\
$7 \%$ & -0.023 & -0.231 & -0.362 \\
$9 \%$ & 0.160 & -0.481 & -0.257 \\
$11 \%$ & 0.354 & 0.358 & 0.296 \\
$13 \%$ & -0.064 & 0.074 & 0.129 \\
\hline
\end{tabular}

\section{(iv) Relationship between body weight and ethanol tolerance}

We have also tested the relationship between ethanol tolerance and body weight of lines (table 7). Again the correlation coefficients were not significant. Van Delden and Kamping (1983) observed, both in $A d h^{F F}$ and $A d h^{S S}$ strains maintained on hexanol, an increase in $\mathrm{ADH}$ activity, ethanol tolerance and body weight. The authors raised the question as to whether there had been a selection for body weight with a concommitant increase in $\mathrm{ADH}$ activity (and con-

Table 7 Relationship between the percentage of male mortality and the fresh weight of lines: values of the Spearman's rank correlation coefficients $(\mathrm{df}=14)$, all were not significant $(P>0.05)$

\begin{tabular}{rrrr}
\multicolumn{4}{c}{ Day of exposure } \\
\cline { 2 - 4 } Conc. & \multicolumn{1}{c}{ D1 } & \multicolumn{1}{c}{ D2 } & \multicolumn{1}{c}{ D3 } \\
\hline $5 \%$ & 0.222 & 0.254 & 0.312 \\
$7 \%$ & 0.276 & 0.257 & $0 \cdot 187$ \\
$9 \%$ & 0.204 & -0.103 & -0.240 \\
$11 \%$ & 0.064 & 0.393 & 0.480 \\
$13 \%$ & -0.323 & 0.381 & 0.232 \\
\hline
\end{tabular}


sequently in ethanol tolerance) or vice versa. For our lines, we can answer that there is no correlation between these three traits.

\section{DISCUSSION}

The results reported here confirm the previous observations that a large degree of genetic variability, affecting the in vitro ADH activity level, exists in the third chromosomes of $D$. melanogaster (Ward, 1975; Barnes and Birley, 1978; McDonald and Ayala, 1978; Maroni et al., 1982). In spite of appreciable environmental and experimental effects on ADH levels, the direction and magnitude of the differences between our third chromosome substitution lines were highly repeatable. Furthermore, our study shown an ethanol tolerance variability linked to the third chromosome. Although the effects of the genetic background on the ethanol tolerance, independently of the $A d h$ polymorphism, were already known (David and Bocquet, 1977, Gibson et al., 1979), this is the first time that the role of any one particular chromosome was demonstrated. Ours is the first study of the relationship between ADH activity and ethanol tolerance in chromosome substitution lines. The results show that in vitro $\mathrm{ADH}$ activity variability-irrespective of the $A d h$ polymorphism--and ethanol tolerance variability are unrelated. Nevertheless only the third chromosome has been surveyed. A study of the $\mathrm{X}$ chromosome and even more importantly the second chromosome should be undertaken in order to see whether this lack of correlation can extend to these other chromosomes. Otherwise, the population from which our third chromosomes originate presents two peculiarities. It is both a Palearctic and vineyard population. Precisely these two kinds of population exhibit higher ethanol tolerance than Tropical (David et al., 1986) and non-vineyard (McKenzie and Parsons, 1974; McKenzie and McKechnie, 1978; Hickey and McLean, 1980) populations. Would the same kind of results have been obtained with a different population (i.e., not very tolerant, such as the Afro-tropical populations, or not from a vineyard)? Such a study is in progress. Moreover one must point out that the use of isogenic lines represents an artificial laboratory situation. Inbreeding being a source of homeostatic disturbances, the differences observed could have nothing to do with the detoxification processes which occur in the wild. Nevertheless, during both the aging of males and the experiment in control vials, no natural mortality was observed, suggesting that weak physiological states was not preponderant in the lines. This observation argues against the between-line mortality variation being due to homeostatic disturbances.

One can also object that the ADH activity which we have measured was on flies which had never been exposed to ethanol. Now, ethanol may have elicited changes on the ADH activity of the flies over the experimental period of the tolerance test. If ethanol has such an effect, it may completely change the correlation of ADH activity on ethanol tolerance. For our part, we have not a response because we have not measured the ADH activity of the survivor flies to the tolerance tests. But two recent reports seem to indicate a lack of such an influence on the adult flies. Indeed, Kerver and Van Delden (1985), from eight tests, have not observed differences in ADH activity between adult flies raised for three days on regular or ethanol supplemented food, except on one occassion where the ethanol food seemed to arrest the age dependent increase in ADH activity. In the same way, Guillen et al. (1987) have not observed changes in ADH activity of adults exposed for one day to a solution of ten per cent ethanol. In contrast, the presence of ethanol in the medium induces a significant increase of ADH activity in the larval stages (McKechnie and Geer, 1984; Kerver and Van Delden, 1985). The existence of two promoters for the Adh locus, one acting during the pre-imaginal stages, the other during the imaginal stage (Benyajati et al., 1983), may occur in this discordance.

The fact remains that our results deviate from the earlier reports (David and Bocquet, 1976; Thompson and Kaiser, 1977; Kamping and Van Delden, 1977) which argued for a positive correlation between ethanol tolerance and ADH activity unrelated to the $A d h$ polymorphism. On the other hand, they agree with the observations of Kerver and Van Delden (1985) and Barbancho et al. (1987). Indeed these latter authors demonstrated that after 90 and 60 generations of raising on ethanol supplemented medium an increase in tolerance was not accompanied by an increase in ADH activity in adults with the same $A d h$ genotype. But again, another situation seems occur in the juvenile life stages since increasing both in ADH activity and ethanol tolerance was observed by Kerver and Van Delden (1985) in these stages, nevertheless the authors concluded that ADH activity was not the only factor involved in the increased tolerance to ethanol.

Though with a different experimental approach, our results corroborate these more recent observations, and strengthen the hypothesis 
that $\mathrm{ADH}$ activity and tolerance to ethanol can be, if not in totality, at least in part, dissociated. As for the Adh locus, for which the differences in activity of its allozymes can be unrelated with differences in ethanol tolerance (see Oakeshott et al., 1984 for debate), the ADH activity variability, linked to the regulatory genes, can be unrelated to the ethanol tolerance variability.

Ethanol is neurotoxic, thus the study of tolerance leads to the study of the efficiency of the process of resistance to it (David, 1988). Although the main role of $\mathrm{ADH}$ in the detoxification of ethanol is well established (David et al., 1976; Middleton and Kacser, 1983; Freeth et al., 1986), the study of in vitro ADH activity alone does not take account of the whole problem. The rate of entry of ethanol via the cuticle, spiracles or gut, the role of the hemolymph (Cohan and Graf, 1985), both the permeability and fluidity of cell membranes (Taraschi and Rubin, 1984; Geer et al., 1986) and the tissue specificity of the ADH expression (Ursprung et al., 1970, Maroni and Stamey, 1983; Fisher and Maniatis, 1986) may also be relevant to ethanol tolerance.

Yet, at low concentrations, ethanol, like other primary alcohols, functions as a food component. It has been shown (Van Herrewege and David, 1974; Deltombe-Lietard et al., 1979; Van Herrewege et al., 1980; Anderson et al., 1981) that the life span of flies deprived of any other food source is extended when ethanol is provided at low concentrations. Moreover, Van Herrewege and David $(1980 ; 1984)$ found that ethanol tolerance (at higher concentrations) and metabolic ethanol utilization (at lower concentrations) may be controlled by different genetic mechanisms. Thus we can agree the hypothesis formulated by Gibson et al. (1979) that higher ADH activity may be relevant in providing energy in flies that are tolerant to environmental alcohols by some mechanism unrelated to $\mathrm{ADH}$ activity. Further experiments, with isogenic lines are in progress in order to investigate the possible relation between ADH activity and the capacity to use ethanol as a metabolic resource.

Acknowledgements One of the authors, H. Merçot, wishes to thank, especially, Dr L. Charles-Palabost who used every effort to equip the laboratory for spectrophotometry. We thank Professor C. Petit for critically reading the manuscript, Drs J. F. McDonald and J. R. David for indicating the enzyme assay procedure and the ethanol test protocol, Dr M. Ashburner for providing the fas balancer stock and Dr. S. F. McEvey for helping with the manuscript. The Venteuil population was collected with Dr S. Ronsseray. This work was supported by C.N.R.S. (UA 693) and by M.E.N. (Aide à la recherche universitaire: Biologie 1983-84).

\section{REFERENCES}

ANDERSON, S. M., MODONALD, J. F. AND SANTOS, M. 1981 Selection at the Adh locus in Drosophila melanogaster: Adult survivalship-mortality in response to ethanol. Experientia, 37, 463-464.

AYALA, F.J. AND MCDONALI, J. F. 1980. Continuous variation: Possible role of regulatory genes. Genetica, 52/53, 1-15.

BARBANCHO, M., SANCHEZ-CANETE, F. J.S., DORADO, G. AND PINEDA, M. 1987. Relation between tolerance to ethanol and alcohol dehydrogenase (ADH) activity in Drosophila melanogaster: Selection, genotype and sex effects. Heredity, $58,443-450$.

BARNES, B. W. AND BIRLFY, A. J. 1978. Genetical variation for enzyme activity in a population of Drosophila melanogaster. IV. Analysis of alcohol dehydrogenase activity in chromosome substitution lines. Heredity, 40, 51-57.

BENYA.IATI, C. SPOEREL, N., HAYMERE, H. AND ASHBURNFR, M. 1983. The messenger RNA for alcohol dehydrogenase in Drosophila melanogaster differs in its $5^{\prime}$ end in different developmental stages. Cell, 33, 125-133.

BIRLEY, A. J. ANI MARSON, A. 1981. Genetical variation for enzyme activity in a population of Drosophila melanogaster. VII. Genotype-environment interaction for alcohol dehydrogenase (ADH) activity. Heredity, 46, 427-441.

CHAMBF.RS, G. K., WILKS, A. V. ANI GIBSON, J. B. 1984. Variation in the biochemical properties of the Drosophila alcohol dehydrogenase alloenzymes. Biochem. Genet., 22, 153-168.

COHAN, F. M. AND (iRAF, I. D). 1985. Latitudinal cline in Drosophila melanogaster for knockdown resistance to ethanol fumes and for rate of response to selection for further resistance. Evolution, 39, 278-293.

DAVID, J. 1962. A new medium for rearing Drosophila in axenic conditions. Dros. Inf. Serv., 93, 472-505.

DAVID, J. R. 1988. Ethanol adaptation and alcohol dehydrogenase polymorphism in Drosophila: From phenotypic functions to genetic structures. In De Jong, G. (ed.) Population Genetics and Evolution, Springer-Verlag, Berlin, pp. $163-172$.

DAVID, J. AND BOCQUET, C. 1977. Genetic tolerance to ethanol in Drosophila melanogaster: Increase by selection and analysis of correleted responses. Genetica, 47, 43-48.

DAVID, J. R. AND VAN HERREWEGE, J. 1983. Adaptation to alcoholic fermentation in Drosophila species: Relationship between alcohol tolerance and larval habitat. Comp. Biochem. Physiol., 74A, 283-288.

DAVID, J., BOCQUET, C., ARENS, M. F. AND FOUILLET, P. 1976. Biological role of alcohol dehydrogenase in the tolerance of Drosophila melanogaster to aliphatic alcohols: Utilisation of an Adh-null mutant. Biochem. Genet., 14, 989-997.

DAVID, J., FOUILLET, P. AND ARENS, M. F. 1974. Comparaison de la sensibilité à l'alcool éthylique de six espèces de Drosophila du sous-groupe melanogaster. Arch. Zool. Exp. Gén., 115, 401-410.

DAVID, J. R., MERÇOT, H., CAPY, P., MCFVEY, S. F. AND VAN HERREWEGE, J. 1986. Alcohol tolerance and Adh allelic frequencies in European and African Drosophila melanogaster populations. Génét. Sél. Evol., 18, 405-416.

DELTOMBE-LIETAERT, M. C., DELCOUR, J., LENELlEMONTFORT, N. AND ELENS, A. 1979. Ethanol metabolism in Drosophila melanogaster. Experientia, 35, 579-581.

DUNN, G. R., WILSON, T. G. AND JACOBSON, K. B. 1969. Agedependent changes in alcohol dehydrogenase in Drosophila. J. Exp. Zool., 171, 185-190. 
FISHER, J. A. AND MANIATIS, T. 1986. Regulatory elements involved in Drosophila Adh gene expression are conserved in divergent species and separate elements mediate expression in different tissues. EMBO J., 5, 1275-1289.

FREETH, A. L., GIBSON, J. B. AND DE COUET, H. G. 1986. The partial characterization of alcohol dehydrogenase null alleles from natural populations of Drosophila melanogaster. Biochem. Genet., 24, 957-972.

GEER, B. W., McKECHNiE, S. W. ANI LANGEVIN, M. I. 1986 The effect of dietary ethanol on the composition of lipids of Drosophila melanogaster larvae. Biochem. Genet., 24, 51-69.

GIBSON, J. B., LEWIS, N., ADENA, M. A. AND WILSON, S. R. 1979. Selection for ethanol tolerance in two populations of Drosophila melanogaster segregating alcohol dehydrogenase allozymes. Aust. J. Biol. Sci., 32, 387-398.

GUILLÉN, E., SANCHEZ-CAÑETE, F. J. S., GARRIDO, J. J., DORADO, G. AND BARBANCHO, M. 1987. Intergenotypic effect of isopropanol ingestion in the further detoxification of ethanol and isopropanol in Drosophila melanogaster. Heredity, 59, 405-411.

HEWITT, N. E., PIPKIN, S. B., WILliAMS, N. AND CHAKRABARTTY, P. K. 1974. Variation in ADH activity in class I and class II strains of Drosophila. J. Hered., 65, 141-148.

HICKEY, D. A. AND McLEAN, M. D. 1980. Selection for ethanol tolerance and Adh allozymes in natural populations of Drosophila melanogaster. Genet. Res., 36, 11-15.

KAMPING, A. AND VAN DELDEN, W. 1978. Alcohol dehydrogenase polymorphism in populations of Drosophila melanogaster. II. Relation between ADH activity and adult mortality. Biochem. Genet., 16, 541-551.

KERVER, J. W. M. AND VAN DELDEN, w. 1985. Development of tolerance to ethanol in relation to the alcohol dehydrogenase locus in Drosophila melanogaster. 1. Adult and egg-to-adult survival in relation to $\mathrm{ADH}$ activity. Heredity, 55, 355-367.

KING, J. J. AND McDONALD, J. F. 1987. Post-translational control of alcohol dehydrogenase levels in Drosophila melanogaster. Genetics, 115, 693-699.

LAURIE-AHLBERG, C. C., MARONi, G., BeWLeY, G. C., LUCCHESI, J. C. AND WEIR, B. S. 1980. Quantitative genetic variation of enzyme activities in natural populations of Drosophila melanogaster. Proc. Natl. Acad. Sci. USA, 77, 1073-1077.

LAURIE-AHLBERG, C. C., WILTON, A. N., CURTSINGER, J. W. AND EMIGH, T. H. 1982. Naturally occuring enzyme activity variation in Drosophila melanogaster. I. Sources of variation for 23 enzymes. Genetics, 102, 191-206.

LEWIS, N. AND GIBSON, J. 1978. Variation in amount of enzyme protein in natural population. Biochem. Genet., 16, 159170.

MARONI, G. AND STAMEY, S. C. 1983. Developmental profile and tissue distribution of alcohol dehydrogenase. Dros. Inf. Serv., 59, 77-79.

MARONI, G., LAURIE-AHLBERG, C. C., ADAMS, D. A. AND WILTON, A. N. 1982. Genetic variation in the expression of Adh in Drosophila melanogaster. Genetics, 101, 431-446.

MCDONALD, J. F. AND AYAlA, F. J. 1978. Genetic and biochemical basis of enzyme activity variation in natural populations. I. Alcohol dehydrogenase in Drosophila melanogaster. Genetics, 89, 371-388.

McDONALD, J. F., CHAMBERS, G. K., DAVID, J. AND AYALA, F. J. 1977. Adaptative response due to changes in gene regulation: A study with Drosophila. Proc. Natl. Acad. Sci. USA, 74, 4562-4566.
McDONALD, J. F., ANDERSON, S. M. AND SANTOS, M. 1980 Biochemical differences between products of the Adh locus in Drosophila. Genetics, 95, 1013-1022.

MCKECHNIE, S. W. AND GEER, B. W. 1984. Regulation of Alcohol dehydrogenase in Drosophila melanogaster by dietary alcohol and carbohydrate. Insect. Biochem., 14, 231 - 242.

MCKENZIE, J. A. AND McKECHNIE, S. W. 1978. Ethanol tolerance and the Adh polymorphism in a natural population of Drosophila melanogaster. Nature, 272, 75-76.

MCKENZIE, J. A. AND PARSONS, P. A. 1974. Microdifferentiation in a natural population of Drosophila melanogaster to alcohol environment. Genetics, 77, 385-394.

MERÇ.OT, H. 1985. Allozyme frequency changes in two inverse sequencies of environments in Drosophila melanogaster. Génét., Sél., Evol., 17, 59-72.

MERÇOT, H. AND HIGUET, D. 1987. ADH activity in two Drosophila melanogaster strains from selection on body weight. Dros. Inf. Serv., 66, 98-99.

MIDDLETON, R. J. AND KACSER, H. 1983. Enzyme variation, metabolic flux and fitness: alcohol dehydrogenase in Drosophila melanogaster. Genetics, 105, 633-650.

MONCLUS, M. AND PREVOSTI, A. 1978-79. Cellars habitat and Drosophila populations. Génét. Ibér., 30-31, 189-201.

OAKESHOTT, J. G., GIBSON, J. B., ANDERSON, P. R., KNIBB, W. R., ANDERSON, D. G. AND CHAMBERS, G. K. 1982. Alcohol dehydrogenase and glycerol-3-phosphate clines in Drosophila melanogaster on the three continents. Evolution, 36, 86-96.

OAKESHOTT, J. G., GIBSON, J. B. AND WILSON, S. R. 1984. Selective effects of the genetic background and ethanol on the alcohol dehydrogenase polymorphism in Drosophila melanogaster. Heredity, 53, 51-67.

PIPKIN, S. B. AND HEWITT, N. E. 1972. Variation of alcohol dehydrogenase levels in Drosophila species hybrids. $J$. Hered., 63, 267-270.

TARASCHI, T. F. AND RUBIN, E. 1985. Biology of disease: Effects of ethanol on the chemical and structural properties of biologic membranes. Lab. Invest., 52, 120-135.

THOMPSON, J. N. AND KAISER, T. N. 1977. Selection acting upon slow-migrating Adh alleles differing in enzyme activity. Heredity, 38, 191-195.

URSPRUNG, H., SOFER, W. H. AND BURROUGHS, N. 1970. Ontogeny and tissue distribution of alcohol dehydrogenase in Drosophila melanogaster. Wilhelm Roux' Archivs, 164, 201-208.

VAN DELDEN, W. 1982. The alcohol dehydrogenase polymorphism in Drosophila melanogaster: selection at an enzyme locus. Evol. Biol., 15, 187-222.

VAN DELDEN, W. AND KAMPING, A. 1983. Adaptation to alcohols in relation to the alcohol dehydrogenase locus in Drosophila melanogaster. Entomol. Exp. Appl., 33, 97-102.

VAN HERREWEGE, J. AND DAVID, J. 1974. Utilisation de l'alcool éthylique dans le métabolisme énergétique d'un insecte: influence sur la durée de survie des adultes de Drosophila melanogaster. C. R. Acad. Sci. Paris, 279, 335338.

VAN HERREWEGE, J. AND DAVID, J. R. 1980. Alcohol tolerance and alcohol utilization in Drosophila: partial independence of two adaptative traits. Heredity, 44, 229-235.

VAN HERREWEGE, J. AND DAVID, J. R. 1984. Extension of life duration by dietary ethanol in Drosophila melanogaster: response to selection in two strains of different origins. Genetica, 63, 61-70.

VAN HERREWEGE, J., DAVID, J. R. AND GRANTHAM, R. 1980. Dietary utilization of aliphatic alcohols by Drosophila. Experientia, 36, 846-847. 
WARI), R. D. 1975. Alcohol dehydrogenase activity in Drosophila melanogaster: a quantitative character. Genet. Res., 26, $81-93$.
WINBERG, J-O., HOVIK, R. AND MCKINLEY-MCKEE J. S. 1985. The Alcohol dehydrogenase alloenzymes $\mathrm{Adh}^{\mathrm{s}}$ and $\mathrm{Adh}^{\mathrm{r}}$ from the fruitfly Drosophila melanogaster: An enzymatic rate assay to determine the active-site concentration. Biochem. Genet., 23, 205-216. 